\title{
A National Pilot Project on Smart City Policy in Thailand: a Case Study on Phuket Khon Kaen Chiangmai Province
}

\author{
Non Naprathansuk \\ School of Administrative Studies, Maejo University, nonnaprathansuk@hotmail.com
}

\begin{abstract}
This research studied Phuket, Khon Kaen, and Chiangmai province policy on smart city. Also this research used smart city concept to provides an essential data and suggestion for executive committee. Thus, This research employed by a qualitative research methodology as a documentary research. Moreover, this research compares three main country which are EU, Japan, Singapore, then Thailand and narrow down to provincial area which is Phuket, Khon Kaen, and Chiangmai. After that it will interpreted and suggested for smart city which are help Phuket, Khon Kaen, governor and chief executives improve quality of life in Phuket, Khon Kaen, and Chiangmai province. The research found that Thailand has initiating on smart country policy and strategy which are focus on ICT system but it does not succeed to implement in province and local level. In provincial level, Phuket, Khon Kaen, and Chiangmai have been initiated but there is no concrete plan also in local level it stills struggle from basic needs of infrastructure. Therefore, this research recommended that Phuket, Khon Kaen, andChiangmai governor and chief executive need to startup action plan which linked both province and local level.
\end{abstract}

Keywords: National pilot, Smart city, Public Policy, Phuket province, Khon Kaen province, Chiangmai province, Thailand 4.0

\section{Introduction}

When we are talking about "smart city" it looks like it is a hot topic for policy makers in urban area and rural area as well, indeed it actually is a national development plan which sprung in many counties around the world in this decade. It begins since the globalization and internet introduced and it has been creating many impact to many dimensions. Therefore, many policy makers have accelerate and catch up a dynamic social and economy changing. Moreover, in academicians is getting relevant on development practitioners. Thus, recently, many articles which is talking and discussing smart city increasing sharply and raise many cases to study specifically in Europe and north America, then later on in Asia. Yet, this topic became a core and important challenge subject in every national development plan.

This papers has four parts the first part is a brief definition on smart city. It focuses on academia definition rather than the practitioners one. However, on the second part it compares a three leading countries that has been engaging smart city in recent situation. The third part it narrows down into Thailand case from the national plan and policy which so called "Thailand 4.0" and smart city to local administration especially in this case study (Maejo municipality). For the last part it is a conclusion and suggestion for Maejo municipality.

However, we should to understand why smart city is necessary in this century and then we can investigate some key aspects and meaning regarding on "smart city" to get a better understanding on this word. the main reason that many cities around the world is facing a challenge in many dimensions also both nation and local government confront with "technology management" or information and Communication Technology (ICT). Moreover, as Falconer (2012:2) explained that more than 50 percent of the world's population lives in cities, placing massive pressure on city infrastructures (transportation, housing, water, power, and city services) many of which require enormous redesign and capital expenditure. Yet, the 600 largest global cities contribute 65 percent of global GDP growth from 2010-2025 and greenhouse-gas emissions (GHGs) are forcing cities to develop sustainability strategies for energy generation and distribution, transportation, water management, urban plaining, and eco-friendly (green) buildings. Also, the economic climate continues to place huge budgetary constraints on cities, which are becoming limited in their ability to respond to these pressures. Therefore, these 
issues, and others, can be mitigated through the adoption of scalable solutions that take advantage of ICT to increase efficiencies, reduce costs, and enhance quality of life. These three main reasons that a bedrock of modern cities in both urban and rural area problems. The solution for fix and reduce this problems is to using technology but also every actors in society such as community, government, private company, and NGOs need to cooperate and participate together.

On the other hand, to understand meaning and definition of smart city, according to Central policy unit, The government of the Hong Kong special administrative region (2015:1-2) pointed out that a smart city can be interpreted as a city which is smarter than traditional ones and capitalizes on new technologies and insights to transform and enhance systems, operations and service delivery. The concept of smart city covers almost every aspect of society and people livelihood, e.g. monitoring of public space, and management of underground pipelines and street illumination in respect of municipal facilities; construction, security, energy management and internal communication in respect of buildings; public transport service such as signal management, road traffic and parking monitoring; home automation and remote management ; highspeed network and cloud storage; and electronic public and business service.

In the same way, as Cohen (2012:1) initiated in 2012 the Smart City Wheel, it consisted of six major components which are; Smart Economy, Smart Mobility, Smart Environment, Smart Citizen, Smart Living, and Smart Government. However, he still pointed out that the first step for smart city is people engagement but the government or local government have to be a leader to let people and community join in policy campaign and process, then policy goals.

In the meantime, Albino, Berardi, and Dangelico (2015:1736) as their studied on smart city definition and argued that smart city evolved along three main directions, representing the perspectives through which the concept has been studied: technology, people, and community. Also their studied directly support to policy makers which could help to identify cities, develop incentives and tools for development of smart cities, and monitor the progresses. In the same way, Policy department A: Economic and scientific policy (2014:17-20) shown that smart city as multi-stakeholder municipally based partnerships aimed at addressing problems of common interest with the aid of ICTs, which underpin "Smart" classification. 'Smart City' initiatives address problems of common interest with the aid of ICTs. To be classified as a Smart City, a city must contain at least one initiative that addresses one or more of the following characteristics: Smart Governance, Smart People, Smart Living, Smart Mobility, Smart Economy and Smart Environment. ICT initiatives based on these characteristics aim to connect existing and improved infrastructure to enhance the services available to stakeholders (citizens, businesses, communities) within a city.

On the other hand, centreforcities ( 2014:3-4) argue that the concept is poorly defined and understood, and is at risk of sitting alongside other well-used but rarely defined notions like "livability" and "sustainability". Also Smart City initiatives can be broadly classified under two main approaches: top down and bottom up. From the top down is Cities adopting this approach become smart by integrating data gathered from different kinds of censors (smart meters and CCTV cameras amongst others) into a single virtual platform in order to manage city operations more efficiently. On the other hand, bottom up is emphasizes the use of new technologies (for example, social media, websites, mobile applications or censoring technologies) and new data (becoming available mainly through open data platforms or censors) as a means to enable citizens to devise solutions, acquire new skills through online learning and improve their interaction with public authorities. Such initiatives include open data platforms that allow the development of new mobile applications or online crowdfunding platforms to fund innovative projects.

In the same way as Chourabi, Nam, Walker, J. Ramon, Mellouli, Nahon, Pardo, School (2012:2289-2290) emphasized that the concept of a smart city itself is still emerging, and the work of defining and conceptualizing it is in progress. Also they pointed out that the conceptual comprehensiveness of a smart city, it could be thought of as a large organic system connecting many subsystems and components. In contrast with Nam and Pardo (2011:186-187) argued that smart city related in terms of technology, organization, and policy. Also smart city still have some risk and challenges in smart city that it could be failed, the failure in managing high risks leads to total failure in technology-driven public sector projects. 85 percent of IT projects fail because of the challenges by non-technical aspects of innovation in large part policy, organization, and management-related risks. Since public sector innovation projects have condition less friendly for innovation. Government agencies are monopolies without competitive pressure to innovate as well as bureaucracies structured to perform core tasks with stability and consistency, and resist change or disruption of those tasks. The public sector cannot easily burden varying costs of learning, experimentation and improvisation. The avoidance of failure is an organizational priority in the public sector and is highly valued because of accountability. As well as Hajduk (2016:34-49) pointed out that the smart city phenomenon developed due to some important challenges such as technological progress, 
innovative devices, knowledge economy, environmental pressures and the political support of global institutions including the United Nations, the European Union and the OECD. Moreover, Hajduk pointed out that smart city is an integrated and comprehensive vision of all aspects of urban life including: the economy, government, transport, green areas, health care and culture.

Therefore, in the modern world most people lives in cities thus, it created a complex society and policy makers or government need a new management to organize in coming digital society. Smart city is one of the solution in this era. However, it still a new and fuzzy, and fancy word to understand the meaning. Many scholars in both academia and practitioners try to define smart city is. As this paper shown earlier we can see that smart city need to involve three main components which are technology, people, and community as a multilevel of stake holder and connected as organic system. However, for policy makers smart city is not only three components but it is a multi-stakeholder at least one initiative linked with people, ICT, government, economy, and etc. for this reason, in next part we raise some cases and compare some city that could represent smart city which is to find out the definition that could be fit on cases.

\section{A Comparative Studies on Smart City: EU, Japan, and Singapore}

This part will compare a cases from three main countries that initiated on smart city. it takes a look on how each country defines and how their approach on smart city which is each of them have a differences perspective, strategies, and policy. In EU case, according to Policy Department A Economic and Scientific Policy (2014:7-63) explained smart city is a city seeking to address public issues via ICT-based solutions on the basis of a multi-stakeholder, municipally based partnership on six characteristics which are Smart Governance, Smart People, Smart Living, Smart Mobility, Smart Economy and Smart Environment . Moreover, in this report their focused on many city in EU and founded that there are Smart Cities in all EU28 countries, but these are not evenly distributed. Countries with the largest numbers are the UK, Spain and Italy, although the highest percentages are in Italy, Austria, Denmark, Norway, Sweden, Estonia and Slovenia. Smart City initiatives are spread across all six characteristics, but most frequently focus on Smart Environment and Smart Mobility. Geographically, there is also a fairly even spread, although Smart Governance projects are mainly seen in the Older Member States of France, Spain, Germany, the UK, Italy and Sweden. Also noteworthy is that some characteristics typically occur in combination, such as Smart People and Smart Living. Also, to approached smart city this report examined using the following categorization:

maturity level 1: a Smart City strategy or policy only

maturity level 2: in addition to level 1, a project plan or project vision, but no piloting or implementation

maturity level 3: in addition to level 2, pilot testing Smart City initiatives

maturity level 4: a Smart City with at least one fully launched or implemented Smart City initiative.

Cities that do not attain maturity level 1 did not qualify as "Smart": clearly there would also be no evidence of them having any of the six characteristics. This is quite clear to measure which city is qualify to count a smart city. Furthermore, in EU, it founded that Citizens tend to have more influence in the neighborhood and participation platform initiatives; government units are important drivers of intelligent traffic systems and participation platforms, and businesses are most influential in resource management systems. There is a mixture of public and private support. Public funding is most important in intelligent traffic system and non-energy-related resource management system initiatives. The energy-related resource management projects often rely on major private financial support. Private sector stakeholders tend to provide in-kind support for testbed micro infrastructures and intelligent traffic systems.

However, according to European Innovation Partnership on Smart Cities and Communities Strategic Implementation (2013: 2-22) the role in EU 2020 which is the EU's strategy for boosting growth and jobs across the region in order to create a smart, sustainable and inclusive economy.110 To further these aims, key targets within five areas have been set on at national and EU-wide levels to be achieved by the 2020, including employment, R\&D, climate change and energy, education, and poverty and social exclusion. EU focuses on employment $75 \%$ of $20-64$ year olds to be employed, R\&D and innovation 3\% of the EU's GDP (public and private combined) to be invested in R\&D or innovation, Climate change and energy Greenhouse gas emissions to be $20 \%$ (or even 30\%, if the conditions are right) lower than $199020 \%$ of energy from renewables $20 \%$ increase in energy efficiency, Education Reduce school drop-out rates below $10 \%$ At least $40 \%$ of 
30-34 year olds have completed third level education, and Poverty and social exclusion which is at least 20 million less people in or at risk of poverty and social exclusion.

In practical, Smart City initiatives can be considered a useful vehicle for cities to achieve their Europe 2020 targets. Cities are conurbations that house a significant number of people, often in densely populated areas. Therefore, cities as Smart entities may be particularly well suited to initiatives addressing local public goods problems, such as energy and climate change. Moreover, the impacts may be highly visible, especially compared with less densely populated areas. The density and diversity of inhabitants (population and business alike) facilitates mutual recognition of problems, mobilization of critical mass, and efficient reallocation and monitoring of roles and responsibilities. These are some potential uses and characteristics of Smart City initiatives:

The Europe 2020 energy target could be addressed through initiatives that focus on Smart Environment or Smart Mobility.

Smart Economy and Smart People initiatives are oriented towards employment and education targets, which include eskills development. Moreover, improving citizens' skills should make them more employable which in turn supports the Europe 2020 employment targets.

Smart Governance and Smart Living initiatives address poverty and social exclusion through measures including improvements to the quality of life, a focus on citizen connectivity (including e-government services) and the use of open data to create citizen services.

The majority of Smart City initiatives have the potential to support innovative growth and R\&D. They are funded by a variety of sources, including government and private companies, which share a common interest in progress in this area. To contribute to the innovation and R\&D target by further stimulating private sector R\&D investment, it is essential that projects are evaluated and lessons learnt from them to enable further development.

In reality, a Smart City initiative aims to make improvements in relation to a number of the Europe 2020 targets. For instance, a project that enhances mobility may make it easier for individuals to travel to the most appropriate school or job (thus contributing to the employment and education targets). In addition, to implement a strategic vision need to backed up by all stakeholders and supported by long-term policies, regulations and frameworks is the basis for an effective and efficient change process. Alignment, both horizontally (different policy fields) and vertically (local, regional, national, EU), using a participatory approach guarantees a holistic view and commitment to the smart-city process for example, Helsinki, Copenhagen, London, Geneva, and Amsterdam.

Finally, in EU which is high density city populations increase strains on energy, transportation, water, buildings and public spaces, so solutions need to be found which are "smart" in both highly efficient and sustainable on the one hand, as well as generating economic prosperity and social wellbeing on the other. Smart city is the best way to achieved by mobilizing all of a city's resources and coordinating its actors using new technologies and forward looking joined-up policies. There are 468 cities in EU with a population of over 100,000 and 240 cities are smart cities identified, based on definition and characteristics of smart city. As a number shown that EU cities strongly engaged to smart city even though each cities has difference focus in smart city characteristic but mostly tries to catch up the criteria on smart city. also the EU commission policy that intend to upgrade an focus on problems which use smart city as a solution to mitigate internal problems.

On the other hand, in Asia Japan is one of the advance and developed country and Japan has been taking a serious action on smart city. Japan has been established Japan Smart Community Alliance (JSCA). There aims focuses on smart community systems which are expected to be an effective means to help resolve many of these issues by harmonizing with existing social infrastructures, thereby creating sustainable societies that can offer increased well-being, safety and security such as Yokohama, Keihanna, Kitakyushu, and Fujisawa

Moreover, according to EU-Japan Centre for Industrial Cooperation report (2014:6-13) shown that the Ministry of Economy, Trade and Industry (METI) has invested in the increasing numbers of Smart City projects since 2010. The promotion of smart energy initiatives is now one of the goals established by the Fourth Energy Strategic Plan. However, the smart city in Japan quite differences approaches from the EU. Japan focuses on sustainable energy due to nuclear accident in Fukushima in March 2011 and the resulting shift away from nuclear power.

The accident in Fukushima Daiichi nuclear plant showed how unstable the energy supply was in Japan. Firstly, it put into light the lack of safety, linked to insufficient risk prevention in the construction of nuclear power plant sites and the 
radioactive threat to local citizens. Considering that there are 50 plants throughout Japan, the risk could not be disregarded and all plants were stopped until security checks were conducted and new safety regulations were applied. Secondly, the sudden shortage of power and the inadequate electricity grid resulted into blackouts and undesired lumps in electricity consumption, showing how constant energy supply cannot be ensured, even for key services in emergency situations, such as communication networks.

Another contested decision of Abe's government lies in the re-start of up to one third of the nuclear power plants. New Regulatory Requirements and New Safety Standards were established by the Nuclear Regulation Authority formed in September 201227 and should be applied to the nuclear plants before plants are used again. Albeit the 2020 goals of GHG emissions targets will not be respected, Japan still aims at lowering its production of carbon dioxide in the long term. Similarly to the pre-Fukushima accident, the focus is jointly put on renewable and clean energy promotion. Energy efficiency is another key tool to contribute to energy security and reduced $\mathrm{CO}_{2}$ emissions. A last key set of policy changes relates to the power grid. The production, transmission and distribution of electricity until the Great East Japan Earthquake was efficient enough that no radical reform was needed, especially as the power companies opposed it, while after 3/11 it was clear that a push towards more efficiency and through energy sector liberalization was necessary.

Furthermore, Japan uses a term of "smart community" rather than smart city and it sounds more socialized as Japan Smart Community Alliance (2015: 2-3) mentioned smart community is a new form of social system that comprehensively manages the supply and demand of energy in the distributed energy systems, optimizes the use and application of energy, and incorporates lifestyle support services including monitoring service for the elderly, through the energy management system utilizing IT and storage energy technologies, while making use of distributed energy resources such as renewable energy and cogeneration. The smart community as the comprehensive approach for the above mentioned social issues will be implemented by the integration of advanced technologies related to environment and energy.

Also, smart community being addressed in Japan has the concept involving smart grid. Whereas smart grid refers to the state being smarter by ICT for electric power system, smart community is the effort of changing social system of a defined area into smarter state with technologies not only for electric power system but also for a variety of public infrastructure including heat supply, water and sewerage, transportation and communications.

Japan thinks smart community needs social system to shape the concepts and smart community is a new system that could solve social problems and improve Japanese life quality. Therefore, we can identified smart community or smart city strategy throughout Japan:

Fostering energy security and efficiency, it intends to enabling substantial $\mathrm{CO} 2$ reductions and energy savings, enabling integration of large amount of renewable energy, enabling stabilized supply of energy, and minimizing energy costs.

Boosting local development economically and socially, it intends to enabling to enhance the standard of living of local residents, offering highly convenient transportation and water services, enabling to develop safe and disaster-resistant society.

Enhancing regional and global competition, it intends to find local solutions to global problems

Therefore, smart city or smart community in Japan has been tackling energy problem especially the policy has been revised according to Fukushima Daiichi nuclear plant disaster and a new strategic plan as a smart community has been launched for enhance Japan next-generation. Thus, the smart community in Japan is the best solution to shaping overall community planning. Meanwhile in Southeast Asia, Singapore quite firstly county that initiated smart city. According to central policy unit (2015:71) Singapore is among the first to launch smart city development. Like other regions, it has a top-down planning framework for overall coordination in terms of strategic positioning, master planning and implementation. Even before the smart city concept was proposed, Singapore had been promoting information and communication technologies, or infocomm, for municipal development since the 1990s. Its smart city strategy aims at making Singapore a quality city-state with a well-connected society powered by the growth and use of infocomm in various area.

However, according to Inter-American Development Bank (2016:3-28) reported that Singapore is somewhat disadvantaged in terms of its geographic location and natural resources. The small island nation sits just one-degree north of the equator, consistently hot and humid year round. The island lacks basic resources; it has no energy deposits, no forests and even no farms. However, despite lacking natural resources and hinterland, Singapore has grown into a global commerce, into 
an Asian tiger economy based on external trade and its skilled pool of human capital. Today, it has a highly developed market economy. The economy depends heavily on financial services, oil-refining, and manufacturing. Therefore, Singapore is pushing towards the vision of being the world's first Smart Nation under the Smart Nation Program developed in 2014, which ideally seeks to harness ICT, networks and data to support better living, create more opportunities, and to support stronger communities. While various cities around the world are experimenting with the concept of "smart city" by making the use of technologies to tackle wide range of urban challenges, Singapore has a much more ambitious and wholeof-nation vision.

The Singapore Government's Smart Nation vision is a response to growing urban challenges of aging population, urban density and energy sustainability. Various stakeholders such as technology builders and entrepreneurs around the world are invited to be involved in this vision to use the nation as a "living lab" to try out new ideas and smart solutions with global potential. A critical role of ICT standards is to enable the integration and interoperability of different ICT systems that is in place for Smart Nation initiatives. Achieving such integration is expected to facilitate the optimal use of resources across different systems.

Moreover, to achieve smart nation, Singapore has many plan in services and wait for implements. Thus Singapore focuses on five key domains which are transportation, home and environment, business and productivity. Health and enable aging, and public sector services. However, the most developed smart services in Singapore is within the Transportation and urban mobility sector; the development of Intelligent Transport System (ITS) has been going on for more than 10 years. Singapore also has a strong e-governance foundation, which they have been incubating since the early 80 s. Also, Singapore has implemented a sophisticated ITS to enhance traffic flow and to keep road traffic running safety. The strength of the ITS in Singapore originates from its holistic approach towards traffic management; ITS work together with other transport initiatives such as free public transportation in pre-morning peak hours, a vehicle quota system, well-functioning public transport system and congestion charge, to enhance overall transport system in the city. Utilizing ITS components, Singapore provides a number of smart transport services for citizens.

Furthermore, smart nation just launched at the very end of 2014 and Singapore has particular advantage in terms of carrying out pilot projects in selected region, partly due to its extensive ownership of public housings, where approximately $80 \%$ of the resident population live, making it easier for government to try out services like in-house displays. Therefore, Singapore case is expected to provide a valuable lesson for all cities especially in Southeast Asian countries. The initiation of smart nation.

\section{The Thailand 4.0 Policy and Smart City}

According to the government public relations department (2016) announced that Prime Minister General Prayut Chan-0cha has cited the "Thailand 4.0" policy as the new direction of the country, to be conducted along with economic reform, in accordance with the 20-year national strategy. In his national address on the program "Return Happiness to the People" on 1 July 2016, the Prime Minister said that in implementing this policy, the Government needed cooperation from all sectors of society on a voluntary basis, so that it would be able to move the country forward, under the vision of "Stability, Prosperity, and Sustainability."

The policy also seeks to promote creativity, innovation, and the application of technology in various economic activities. The objective is to create equilibrium between the environment and society. Thailand 4.0 is a new economic model to develop Thailand into a valued-based economy. The new model will change the country's traditional farming to smart farming, traditional SMEs to smart enterprises, and traditional services to high-value services. From the past up to the present, Thailand has passed through three economic development models. In the first model, Thailand 1.0, emphasis was placed on traditional agricultural development. The second model, Thailand 2.0, focused on light industries, which helped upgrade the country's economy from the low-income to middle-income status. The third model, Thailand 3.0, emphasized heavy industries for continued economic growth.

In Thailand 3.0, the country has become stuck in the middle-income trap and faces disparities and imbalanced development. In the next period, Thailand 4.0, the country needs to pull itself out of the middle-income trap and deal effectively with disparities and the imbalance between the environment and society. This model will be carried out along with the 20-year national strategy and economic reform through the mechanism of "public-private-people partnership." It will transform Thailand's comparative advantage into a competitive advantage. In this regard, new engines of growth will 
be introduced. Prime Minister General Prayut stated that 10 target industrial groups will become new engines of growth. For instance, in the food and agriculture group, the Government has established the Food Innopolis ${ }^{1}$ to promote the processing of agricultural products on a full-cycle basis. In the health group, he said, research and development, herbal production, alternative medicine, and local wisdom have been given a major boost, along with health tourism. The Government intends to develop "herb city" and "medical hub." Moreover, robotics and smart electronics will be emphasized, as they will be in great demand in various industries. Thailand 4.0 also consists of seven industries that are considered the backbone of the digital economy.

Therefore, for smart city in Thailand context and a new policy from a national road map. Thailand focuses on build a county wide-high-capacity digital infrastructure, boost the economy with a digital technology, create a quality and equitable society through digital technology, transform into digital government, develop workforce for the digital era, and build trust and confidence in the use of digital technology. Moreover, Thailand has been initiated on smart city by pick up some provinces to experiments which are Nakhon Nayork which is announced in 2013 and the project aims to improve public services by developing wide-area communication networks and to enhance the competitiveness of provinces by making regional cities more competitive especially focuses on communication infrastructure development. Then Phuket, this province has been initiated for creating an environment that supports the development of digital service innovation as well as to encourage the concrete development of the digital industry and innovation.

Furthermore, the government aims to develop Thailand into a hub of digital services in the ASEAN region and a hub for connecting with other countries worldwide to attract digital workers, digital investors, and software companies across the world to work and invest in Thailand in order to create new Startups and efficiently drive the Digital Economy. Also, Chiangmai, and Khonekaen. This cities will be a pilot provinces after that the government will expands to nationwide within 2019.

Also, on March 23, 2016 Digital Economy Promotion Agency (DEPA) (2016) reported that Mr. Pawin Chamniprasart, Governor of Chiangmai Province, Mr. Narong Tananuwat, Honorary Chairman of Chiangmai Province Chamber of Commerce, to attend a meeting to discuss and exchange information concerning Smart City Project launched at Incheon City and Seongnam City, South Korea. The ecosystems in both cities are similar to that of Chiangmai Province, making it a perfect choice to establish collaboration with Chiangmai Smart City Project. In addition, a Letter of Intent signing ceremony was also held to establish collaboration between Chiangmai Province and Seongnam City for Smart City Development at Seongnam City Hall where information on Chiangmai Province was also presented to top-ranking executives from Seongnam City. The event was also joined by software and digital content entrepreneurs from over 40 companies. Furthermore, such collaboration between Chiangmai Province and Seongnam City in developing Smart City also led to other collaboration projects including:

International ICT Volunteer (IIV) - A project initiated under the collaboration between International Telecommunication Union (ITU) and Seongnam City to encourage undergraduate ICT students in helping to promote ICT development among local communities Chiangmai Province.

Workshop organized at Seongnam City to promote participation of Smart City experts in formulating Chiangmai Smart City Development Plan.

Startup Promotion Project at Chiangmai Province - A collaboration project that involves the participation of leading companies and Startups from Seongnam City in developing Startup businesses in Chiangmai in order to build Startup Ecosystem CM. In addition, a discussion meeting was also held on the same day regarding how to establish suitable operational procedure to ensure quick and efficient result.

In addition, Leesa-Nguansuk's Bangkok Post writer (2016) reported that Chiang Mai will also serve as a testing ground for new ways of applying information and communication technology to make optimal use of local strengths. The northern

\footnotetext{
1 The Internet of things (loT) is the inter-networking of physical devices, vehicles (also referred to as "connected devices" and "smart devices"), buildings, and other items embedded with electronics, software, sensors, actuators, and network connectivity which enable these objects to collect and exchange data.
} 
province is mapping out its future. Also, Chiang Mai aims to become a development Centre for enterprise software, digital content and animation, the loT ${ }^{1}$, embedded systems for automation and connected vehicles and tech startup businesses.

Recently in 2017, he also mention that Chiang Mai smart city is dedicated to promoting smart agriculture, reducing air pollution, enhancing tourist experience and sustaining the city and social development through the use of information and communications technology. The Digital Economy Promotion Agency (Depa), formerly known as Software Industry Promotion Agency (SIPA is a Public Organization), is embarking on a 36.5-million-baht smart city project to develop Chiang Mai as an innovation-driven destination.

Moreover, Digital Economy Promotion Agency or formerly known as Software Industry Promotion Agency (Public Organization) created Smart City Project in Chiang Mai Province. The agency provided the project with consultation and promotion of technology application to agricultural industry, tourism and city management. The project is based on 3 concrete operation plans: 1. Smart Environment in which the agency teams up with Maejo University in technological development to eliminate smoke and haze problems usually peaking in March; 2 Smart Agriculture which applies technological development to improve agriculture in Chiang Mai where agricultural areas occupy more than $80 \%$ of total areas; and 3. application of technology to solve transportation problems and support tourism.

In the meantime, Maejo municipality located in Sansai district, Chiangmai where Maejo University located in this area as well. However, according to Maejo municipality website it does not provides sufficient information and most of information on website does not up to date. Their yearly plan, three years plan, and strategic development plan still focus on basic needs of infrastructure such as electricity, water supply, water pipeline, road, and waste water pipeline. This means the national policy and province strategic plan do not implement or transfer into local level. Even though Maejo municipality located in Chiangmai where it is a pilot project for smart city. in the same way with Nantawan Wongkachonkitti (2016:367) founded that during the implementation stage, there were some obstacles such as unclear of the policy, rack of readiness, rack of understanding, insufficient budget, poor infrastructure, and rack of concrete guidelines.

Therefore, to find solution government needs to concrete focuses on smart city and needs to put smart city plan into local level which is a fundamental and bedrock in Thai society. Moreover, it needs to promotes and let's local community join in smart city project as a variety of stakeholders. Especially, local community has to be a center and connected and integrated to government agencies in many levels via ICT which creates a new innovation that suitable for each local context.

\section{Conclusion and Suggestion}

Smart city is a new word and it is not standard and variety of definition. Also, it depends on people in different sectors. Smart City concepts requires a combination of smart efforts to improve quality of life and it promotes economic growth, sustain environment and energy. The key concept of smart include six dimensions which are: Smart Economy, Smart Mobility, Smart Environment, Smart Citizen, Smart Living, and Smart Government.

All of six dimensions need to connected with ICT and ICT based concepts such as big data, open data, Internet of Things (loT), data accessibility and management, data security, and mobile broadband. In Europe, Japan, and Singapore cases shown that all of them initiated and some cities has been engaged. However, in EU case, smart city is a new and best solution for improve a quality of life for European. Meanwhile, Japan creates a smart community which focus on social network and it is a new solution for sustain energy since the Fukushima disaster and aging problem. On the other hand, Singapore engaged on smart nation for sustain natural resources and population density.

Moreover, Thailand also initiated on smart city and created a blueprint of national plan which so called Road Map of Thailand 4.0. This national plan tries to develop Thailand into a digital society. However, to implements this plan there are many problems from top-down level especially in local community. Therefore, to achieve and reach the national policy goal Thai government needs more promote and make a concrete plan from the top level to local level. In the same way, local administrative organizations need to start up and promote their community into smart community or smart city which can start up on smart infrastructure. Smart infrastructure is a foundation for all of the key themes in six dimensions. The core characteristic that underlies is they are connected and that they generate data and connected community. For instance, a smart building and mobility integrate the different physical systems present in an intelligent way to ensure that all the

1 About this, you can watch the video by Professor Amanda Vickery who journeys from Renaissance Italy to the Dutch Republic and discovers a hidden world of female artistry: The Story of Women and Art 1 -2-3. https://www.youtube.com/watch?v=SCkab-v_03k 
systems act together in an optimized and efficient manner. Smart building and mobility management systems can improve building and save energy and efficiency, reduce waste and ensure an optimum usage of water, electric, gasoline with operational effectiveness and occupant satisfaction. thus, in this case this research recommended to Chief executive and executive committee need to startup which propose smart city development proposal which should focuses on smart city with is could start up on smart infrastructure to community.

\section{References}

[1] Albino, V., Berardi, U., \& Rosa Maria Dangelico. (2015). Smart cities: definitions, dimensions, and performance and Initiatives. Journal of Urban Technology, 3-21. Retrieved from www.ifkad.org/Proceedings/2013/papers/session7/103.pdf

[2] Boyd Cohen. (2013, May 14). The Smart City Wheel. Retrieved from SMART \& SAFE CITY: http://www.smartcircle.org/smartcity/blog/boyd-cohen-the-smart-city-wheel/

[3] Catriona Manville, g. C., Cave, J., Millard, J., Pederson, J. K., Thaarup, R. K., Liebe, A., . . Bas Kotterink. (2014, January). Mapping Smart Cities in the EU. Retrieved from Europan Union: www.europarl.europa.eu/RegData/etudes/.../IPOL-ITRE_ET(2014)507480_EN.pdf

[4] Central policy unit the government of the Hong Kong special administrative. (2015, September). Research report on smart city. Retrieved from Central policy unit the government of the Hong Kong special administrative:

http://lp.search.gov.hk/search.html?query=smart+city\&gp0=cpu_r2_home\&gp1=cpu_r2_home\&tpl_id=cpu_r2 \&ui_lang=en\&ui_charset=utf\&\&web=this\&mainbar8. $x=0$ \&mainbar8. $y=0$

[5] centreforcities. (2014, May). Smart Cities. Retrieved from centreforcities: http://www.centreforcities.org/reader/smart-cities/what-is-a-smart-city/1-smart-cities-definitions/

[6] Chourabi, H., Nam, T., Walker, S., Gil-Garcia, J. R., Mellouli, S., Nahon, K., ... Hans Jochen School. (2012). Understanding Smart Cities: An Intergrative Framework. 45th Hawaii International Conference on System Sciences (pp. 2289-2297). Hawaii: IEE Computer Society.

[7] Digital Economy Promotion Agency. (2016, March 25). http://www.depa.or.th. Retrieved from SIPA (Chiangmai Branch) Collaborating with Seongnam City, South Korea in Driving Chiangmai Smart City: http://www.depa.or.th/en/news/sipa-chiangmai-branch-collaborating-seongnam-city-south-korea-drivingchiangmai-smart-city

[8] European Innovation Partnership on Smart Cities and Communities Strategic Implementation plan. (2013, 10 14). European commision. Retrieved from http://ec.europa.eu/eip/smartcities/: chromeextension://oemmndcbldboiebfnladdacbdfmadadm/http://ec.europa.eu/eip/smartcities/files/sip_final_en.pdf

[9] Falconer, G., \& Shane Mitchell. (2012). Smart City Framework ASystematic Process for Enabling Smart+Connected Communities. Retrieved from www.cisco.com: www.cisco.com/c/dam/en_us/about/.../Smart-City-Framework.pdf

[10] Lee, S. K., Kwon, H. R., Cho, H., Kim, J., \& Donju Lee. (2016, June). International Case Studies of Smart Cities Singapore, Republic of Singapore. Retrieved from Inter-American Development Bank: http://www.iadb.org/en/topics/emerging-and-sustainable-cities/international-case-studies-of-smartcities,20271.html

[11] Manville, C., Cochrane, G., Cave, j., Millard, J., Pederson, J. K., Thaarup, R. K., . . Bas Kotterink. (2014). Mapping Smart Cities in the EU. Retrieved from Policy Development A Economic and Scientific Policy: http://www.europarl.europa.eu/RegData/etudes/.../IPOL-ITRE_ET(2014)507480_EN.pdf

[12] Nantawan Wongkachonkitti. (2016). Smart service policy in Thailand (in Thai language). Research and development Valaya Alongkron Rajabhat University, 365-377.

[13] Pham Clarisse. (2014, October). Smart Cities in Japan An Assessment on the Potential for EU-Japan Cooperation and Business Development. Retrieved from EU-Japan Centre for INdustrail Cooperation: http://www.eu-japan.eu/publications/smart-cities-japan

[14] Slawomira Hajduk. (2016). The concept of a smart city in urban management. Business, Management and Education, 34-49.

[15] Suchit Leesa-Nguansuk. (2016, August 1). A tale of smart cities. Retrieved from Bangkok Post: http://www.bangkokpost.com/tech/local-news/1049621/a-tale-of-smart-cities 
[16] Suchit Leesa-Nguansuk. (2017, February 11). Chiang Mai to become smart city. Retrieved from Bangkok Post: http://www.bangkokpost.com/tech/local-news/1196657/chiang-mai-to-become-smart-city

[17] Taewoo Nam and Theresa Pardo. (2011). Smart City as Urban Innovation: Focusing on Management, Policy, and Context. 5th International Conference on Theory and Practice of Electronic Governance (ICEGOV2011) (pp. 185-194). Tallinn, Estonia: ACM New York, NY, USA .

[18] Thailand Local Government Summit 2016. (2016, November 23). thailandlocalgovernmentsummit. Retrieved from chrome-

extension://oemmndcbldboiebfnladdacbdfmadadm/http://thailandlocalgovernmentsummit.com/wpcontent/uploads/Detail-Thailand-Local-Government-Summit-2016.pdf

[19] The Economist Intelligence Unit. (2016). Startup My City. Retrieved from http://www.economist.com/: http://startupmycity.economist.com/startup-my-city-smart-sustainable-cities-asia/

[20] The Japan Smart Community Alliance. (2015, may). smart-japan.org. Retrieved from chromeextension://oemmndcbldboiebfnladdacbdfmadadm/https://www.smartjapan.org/english/vcms_lf/Resources/JSCApamphlet_eng_web.pdf

[21] United Nations. (2016, May 9-13). Smart cities and infrastructure. Retrieved from unctad: chromeextension://oemmndcbldboiebfnladdacbdfmadadm/http://unctad.org/meetings/en/SessionalDocuments/ecn162 016d2_en.pdf 